\title{
The measurement of soil stiffness in the triaxial apparatus
}

\author{
R. J. JARDINE, N. J. SYMES and J. B. BURLAND (1984). Géotechnique 34, No. 3, 323-340
}

Dr J. H. Atkinson and Mr J. S. Evans, The City University, London

\section{INTRODUCTION}

The Authors describe results of triaxial tests using a new device for accurate measurement of axial strain. Measurement of soil stiffness sufficiently accurate for many practical design calculations may also be achieved using conventional axial strain measurements together with simple and inexpensive modifications to testing equipment and procedures.

\section{AXIAL STRAIN ERRORS IN \\ TRIAXIAL TESTS}

Figure 1 shows a diagrammatic section of a standard Bishop and Wesley stress path cell (Bishop \& Wesley, 1975). The change in sample length is usually measured using an external displacement transducer which records a deflexion $\Delta_{\mathbf{H}}$. It may be noted that, with the transducer attached to the top of the triaxial cell, the cell is not part of the measuring system and errors due to expansion of the cell with changing ccll pressure are eliminated.

There is only one Bellofram diaphragm between the sample and the transducer; it is loaded in compression and the error $\Delta_{R}$ due to compression of the rubber is negligible. In some stress path cells axial strains are calculated from the volume $\Delta V_{\mathrm{b}}$ of fluid entering or leaving the lower Bellofram chamber and, in these apparatuses, substantial and variable errors occur due to stretching of the Bellofram in tension and due to compression of the loading fluid and air trapped in the Bellofram roll.

Deflexions $\Delta_{L}$ of some current designs of internal load cells are not negligible but they are reasonably linear and appropriate corrections can be applied to the measured deflexions. The compliance of the load cells in the Writers' current apparatus is equivalent to an error in axial strain of approximately $0.08 \%$ per $100 \mathrm{kPa}$ deviator stress for a $38 \mathrm{~mm}$ dia. sample, which corresponds closely to the value $5.4 \times$ $10^{-4} \mathrm{~mm} / \mathrm{N}$ quoted by the Authors for the compliance of the load cell and ram together. Load cells recently commissioned by the University of Surrey (Clayton \& Matthews, 1984) and now available from Wykeham-Farrance Ltd are very much stiffer and are reported to have compliances of the order of $5.0 \times 10^{-6} \mathrm{~mm} / \mathrm{N}$ equivalent to an error in the axial strain of approximately $0.0007 \%$ per $100 \mathrm{kPa}$ deviator stress for a $38 \mathrm{~mm}$ dia. sample.

\section{BEDDING, SEATING AND TILTING ERRORS}

As a first stage of a triaxial test the sample is compressed isotropically or anisotropically, drained (i.e. consolidated) or undrained. The initial axial effective stress depends on the initial state of the sample and on the conditions of the test but it will usually be sufficient to bed the platens into the sample such that there will be negligible additional bedding during the first stage of triaxial compression. If additional bedding does occur at the start of loading this can be eliminated simply by raising the initial stress state by an amount equal to the increment of axial stress over which the bedding was observed.

Errors due to seating and tilting between the load cell and the top platen can be eliminated by attaching the platen to the load cell at the very start of the test (i.e. before the initial stresses are applied) rather than just before the deviator stress is applied as is usual practice. The load cell and top platen can be joined inside the triaxial cell body using a simple suction cap device such as the one developed at Imperial College by Skinner (1982). The suction cap device was designed to allow extension tests for which $\sigma_{\mathrm{a}}<\sigma_{\mathrm{r}}$ and, once the top platen and the load cell have been joined, the pressure in the lower Bellofram chamber must be altered as the cell pressure is altered.

\section{RATE OF LOADING}

The Authors' tests were carried out at a constant nominal rate of axial strain of $4.5 \%$ per day although data given in their Table 2 indicate that the actual rates of straining were somewhat less than the nominal rates. Constant rate of 


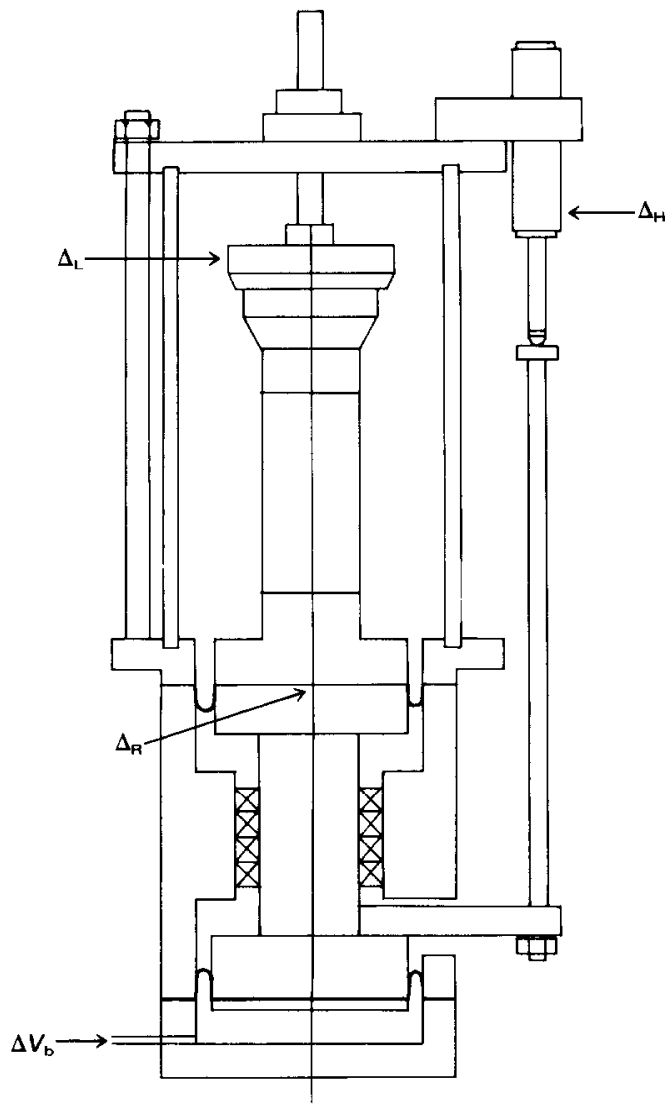

Fig. 1. Sources of error in measurement of axial strain in a Bishop and Wesley stress path cell

straining of relatively stiff samples implies very rapid loading particularly for small strains and, to avoid excessive rates of change of stress, it is necessary to modify the test to constant rate of stress change. As samples approach failure, however, they become relatively soft and constant rate of strain loading is necessary to prevent sudden and uncontrolled failure. Thus, to observe the complete stress-strain behaviour of a soil sample it is necessary to carry out tests which begin as constant ratc of stress change loading when the strains are small and which change to constant rate of strain loading when the strains are large towards failure. Fquipment suitable for routine triaxial tests of this kind has been described by Atkinson (1985).

To illustrate the importance of constant stress rate and constant strain rate loading three isotropically consolidated undrained triaxial compression tests were carried out in a Bishop and
Wesley cell on identical samples of reconstituted Speswhite kaolin $(L L=63, P I=34)$. The test data were analysed using the stress parameters $q^{\prime}=\sigma_{\mathrm{a}}{ }^{\prime}-\sigma_{\mathrm{r}}^{\prime}$ and $p^{\prime}=\frac{1}{3}\left(\sigma_{\mathrm{a}}{ }^{\prime}+2 \sigma_{\mathrm{r}}{ }^{\prime}\right) \quad$ following Wood (1984) rather than the parameters used by the Authors but this does not affect the present discussion. The samples were prepared by $K_{0}$ consolidation from slurry to a nominal mean effective stress $p^{\prime}=40 \mathrm{kPa}$, isotropic consolidation to $p_{c}{ }^{\prime}=300 \mathrm{kPa}$ and isotropic swelling to $p_{0}{ }^{\prime}=60 \mathrm{kPa}$. The isotropic consolidation and swelling stages were carried out by drained loading and unloading in the Bishop and Wesley cell and, to prevent seating errors, a suction cap device was used to join the top platen to the load cell from the very start of consolidation.

During the triaxial compression stages sample A was loaded throughout at a nominal rate of axial strain $\dot{\varepsilon}_{\mathrm{a}}=1.7 \%$ per hour; sample $\mathrm{B}$ was loaded throughout at a nominal rate of deviator stress change of $q^{\prime}=18 \mathrm{kPa} / \mathrm{h}$; sample $\mathrm{C}$ was loaded at $q^{\prime}=18 \mathrm{kPa} / \mathrm{h}$ to an axial strain of $\varepsilon_{\mathrm{a}}=1.5 \%$ and thereafter it was loaded to failure at $\dot{\varepsilon}_{\mathrm{a}}=3 \cdot 3 \%$ per hour. Fig. 2(a) shows the rates of change of deviator stress for the three tests and Fig. 2(b) shows the corresponding rates of axial strain. These data illustrate the very high rates of stress change at the start of the strain-controlled loading test and the very high rates of strain at failure in the constant stress rate test but the hybrid loading test (test $\mathrm{C}$ ) had acceptable rates of loading and straining at all stages of the test.

Figure 3(a) shows the stress-strain curve for the hybrid loading test (test C) plotted with a logarithmic scale for axial strain and Fig. 3(h) shows the undrained secant Young's modulus $E_{u}$ normalized with respect to the undrained shear strength $c_{1}$ plotted against the axial strain. These correspond, for example, to Figs 7(b) and 7(c) of the Authors' Paper. There was no evidence of bedding, tilting or seating errors in any of the stress-strain curves and there is no indication in Fig. 3 of the change from stress-controlled to strain-controlled loading.

The general form of the data in Figs 3(a) and 3 (b) is similar to that given by the Authors. Since they examined different soils with different stress historics, no dircet comparisons can be made but the same orders of magnitude for the stiffness have been measured in both sets of tests. In the Writers' tests data have not been obtained at strains smaller than about $0.01 \%$ whereas the Authors give data corresponding to axial strains of the order of $0.001 \%$. Thus, although the two sets of data may be equally accurate the Authors' equipment is capable of higher resolution. 


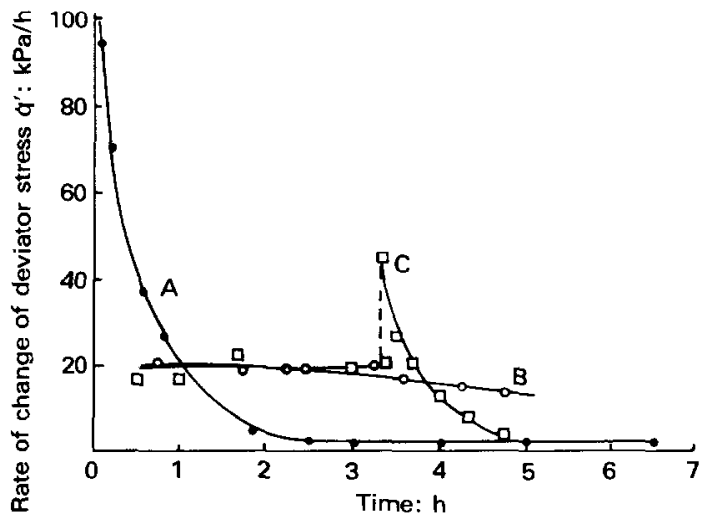

(a)

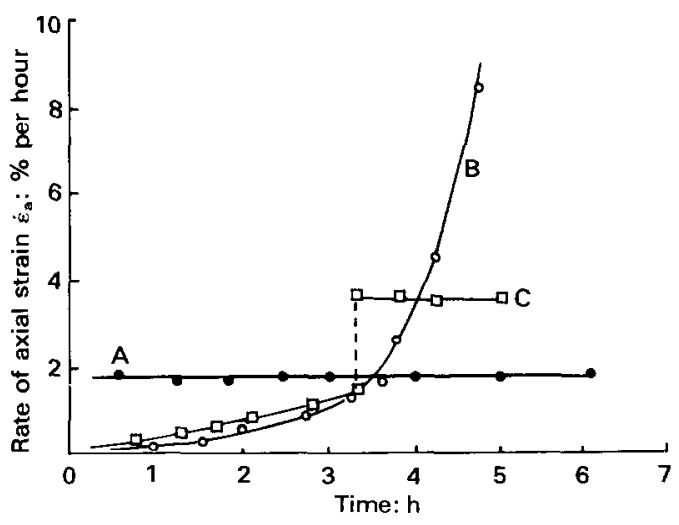

(b)

Fig. 2. Loading rates in triaxial tests: test $A$, conventional strain-controlled loading; test $B$, constant rate of stress change loading; test $C$, hybrid loading

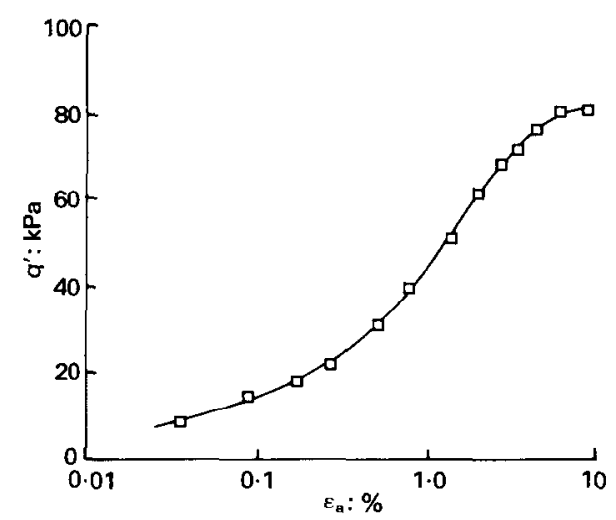

(a)

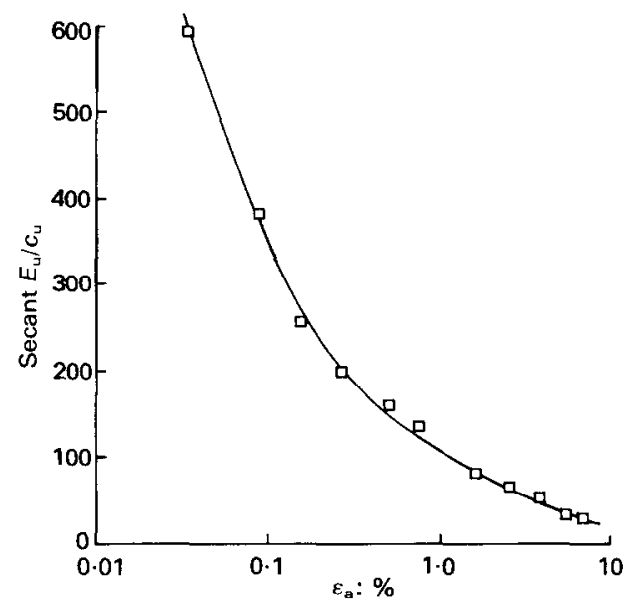

(b)

Fig. 3. Results for test C: hybrid loading

\section{DISCUSSION}

As noted by the Authors, more research is required into the factors controlling the stiffness of soils but their work has demonstrated that it is possible to obtain design parameters which correspond approximately to those inferred from observations of ground movements from laboratory tests with special instrumentation. The Writers have observed similar stress-strain characteristics in laboratory tests using conventional instrumentation but with modified testing procedures. Both sets of results should encourage further research into development of simple equipment and procedures for routine laboratory testing of soils to determine soil deformation parameters for design.

\section{REFERENCES}

Atkinson, J. H. (1985). Simple and inexpensive pressure control equipment for conventional and stress path triaxial testing of soils. Géotechnique 35, No. $1,61-63$.

Bishop, A. W. \& Wesley, I. D. (1975). A hydraulic triaxial apparatus for controlled stress path testing. Géotechnique 25, No. 4, 657-670.

Clayton, C. R. I. \& Matthews, M. E. (1984). Private communication.

Skinner, A. E. (1982). Private communication.

Wood, D. M. (1984). On stress parameters. Géotechnique 34, No. 2, 282-287.

\section{Authors' reply}

In their discussion the Writers claim that errors due to seating and tilting between the load 


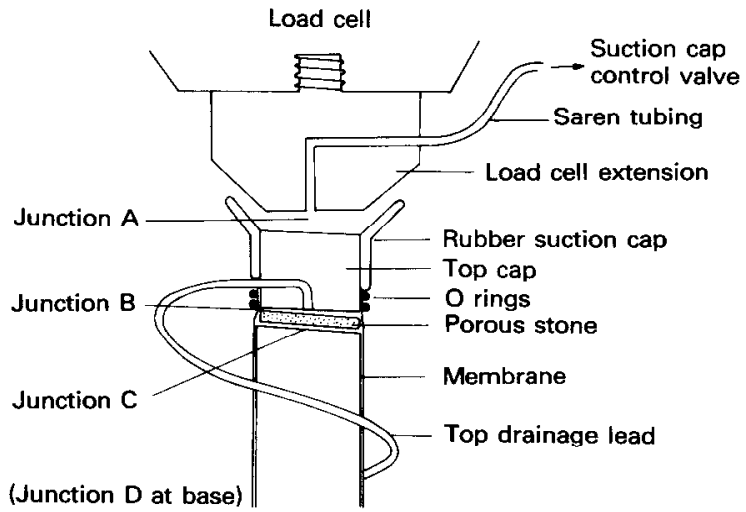

Fig. 4. An exaggerated view of a triaxial sample before connection of load cell and suction cap

cell and the top platen can be eliminated by connecting the top platen to the load cell at the start of the test using a simple suction cap. The use of a suction cap offers advantages when the radial stress exceeds the axial stress. However, experience at Imperial College over the last ten years shows that the procedure for connecting the suction cap to the load cell is notoriously difficult and in many cases does not eliminate bedding errors.

The reasons for this can be illustrated by referring to Fig. 4. The top of any soil sample, reconstituted or intact, is seldom perfectly flat, horizontal or in line with the load cell extension. Moreover the tug of a top drainage lead affects the alignment as do small quantities of air trapped at junctions $\mathrm{B}$ and $\mathrm{C}$.

When contact is first made with the rubber cap and the suction is applied the sample is wrenched into alignment and for a short period deviator forces develop which have been found to be as high as $20 \mathrm{~N}$. Thus non-uniform stresses are set up in the sample. For soft samples experiencing significant consolidation subsequent to the connection phase, junctions $A-D$ will close up and the stress inhomogeneities will be reduced. Thus tests such as those reported by Gens (1982) and the Writers are likely to have avoided significant bedding and tilting errors.

With dense or stiff samples these problems are less easily avoided. Daramola (1978) carried out his anisotropically consolidated tests on sands using exactly the procedures proposed by the Writers, but used internal linear variable differential transformer (LVDT) instrumentation to check the external strain measurements. Costa-Filho (1980) used a similar technique to investigate the small strain behaviour of London Clay. These results are best summarized by quoting directly from Costa-Filho (1980). 'Anisotropic consolidation with the horizontal stress greater than the vertical does not reduce the bedding errors on subsequent shearing. It is to be noted that Daramola (1978) found that during $K_{0}$ swelling of sand bedding errors were reobserved after their suppression during consolidation and persisted on subsequent shearing.' The results presented in the Paper also show that bedding and tilting reappeared with overconsolidated samples of the low plasticity clay tested from $K_{0}$ conditions.

In many tests it is not desirable to induce large strains through consolidation, and unconsolidated conditions are by far the most common. Costa-Filho (1980) and Jardine, Brooks \& Smith (1985) used direct strain measurements with LVDTs and electrical resistance gauges to show that the state of strain inside routinely prepared samples is not uniform in such tests. Tests on intact chalk and London Clay showed that tensile strains could persist to deviator stress levels of $100 \mathrm{kPa}$ and $1400 \mathrm{kPa}$ respectively, and so conventional measurements over the initial portion of the stress-strain curve are not valid. In these cases neither the suction cap connection nor reconsolidation to the initial stresses would greatly improve the accuracy of external measurements.

Returning to the problems of system compliance, the Authors have found the following additional difficulties with external measurements

(a) air trapped at junction $\mathrm{A}$ can make the connection between top cap and sample less than rigid

(b) the suction cap can slip

(c) load cell deflexion characteristics are imper- 
fectly linear as shown in Fig. 5, and the gap $G$ of the loose fitting star can seriously confuse tests where the stress path crosses the $\sigma_{\mathrm{A}}-$ $\sigma_{\mathrm{R}}=0$ axis

(d) the displacement transducer is not connected to the ram and the load cell in a perfectly rigid way.

We agree with the Writers that the use of stiffer load cells is to be encouraged, provided that temperature insensitivity is not sacrificed.

The Writers describe a hybrid control system for the shearing phase of a test to avoid excessive rates of stress change during the early stages. Gens (1982) used the same procedure for an extensive test programme on Lower Cromer Till. It should be emphasizcd that if a constant rate of stress change is to be employed it is necessary to know the failure strain in advance. For the tests described in the Paper this was not the case as the $K_{0}$ normally consolidated soil failed at $0 \cdot 1 \%$ strain, the sand at $11.0 \%$ and the chalk at around $0.08 \%$. If it is necessary to limit the rate of change of stress the Authors wonder whether it would not be simpler to employ a reduced rate of strain initially followed by a transition to a faster rate of strain during later stages of the test.

Finally the Writers draw attention to the fact that the techniques described in the Paper give at least an order of magnitude better resolution than conventional strain measurements (which are themselves prone to serious bedding crrors). We wish to emphasize that the accurate determination of the stiffness of the soil at strains in the range $0.001-0.01 \%$ is of more than academic interest. Jardine, Fourie, Maswoswe \& Burland (1985) have analysed the results of a number of field measurements and shown that the bulk of soil which contributes to the displacements of plates, footings, piles and excavations in stiff clays under working conditions experiences shear strains less than $0 \cdot 01-0 \cdot 1 \%$. The device described in the Paper can be used

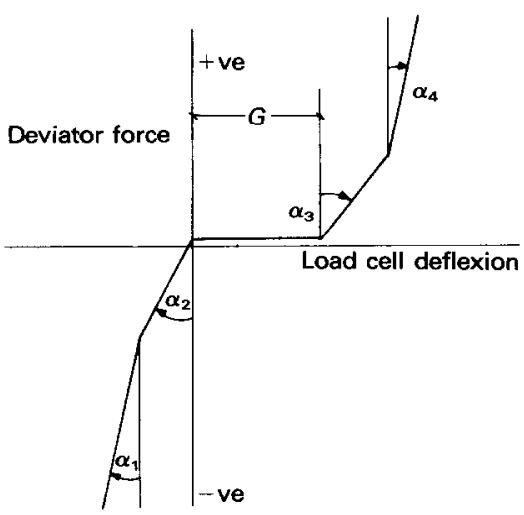

$G$ represents the gap in the loose fitting star, and usually corresponds to around $0.15 \%$ axial strain for a sample $78 \mathrm{~mm}$ high

Fig. 5. Load cell compliance characteristics (after Costa-Filho, 1980)

for routine testing since it is simple to mount and is not damaged when the sample is taken to failure.

\section{REFERENCES}

Costa-Filho, L. M. (1980). A laboratory investigation of the small strain behaviour of London Clay. PhD thesis, University of London.

Daramola, O. (1978). The influence of stress history on the deformation of sand. $\mathrm{PhD}$ thesis, University of London.

Gens, A. (1982). Stress-strain and strength characteristics of a low plasticity clay. $\mathrm{PhD}$ thesis, University of London.

Jardine, R. J., Brooks, N. J. \& Smith, P. R. (1985). The use of electrolevel transducers for strain measurements in triaxial tests on weak rocks. Int. $J$. Rock Mech. Min. Sci., in the press.

Jardine, R. J., Fourie, A. B., Maswoswe, J. \& Burland, J. B. (1985). Field and laboratory measurements of soil stiffness. Proc. 11th Int. Conf. Soil Mech. Fdn Engng, San Francisco, 11-16 Aug. Rotterdam: Balkema. 